Case Report:

\title{
Simultaneous Diffuse Idiopathic Hyperostosis, Ossification of the Posterior Longitudinal Ligament and Ligamentum
} Flavum

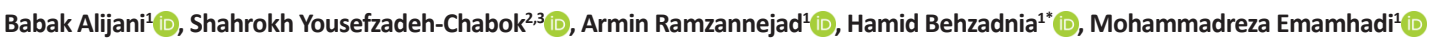

1. Department of Neurosurgery, Poursina Hospital, Guilan University of Medical Sciences, Rasht, Iran

2. Neuroscience Research Center, Guilan University of Medical Sciences, Rasht, Iran

3. Guilan Road Trauma Research Center, Guilan University of Medical Sciences, Rasht, Iran

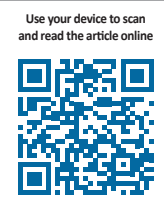

Citation Alijani B, Yousefzadeh-Chabok Sh, Ramzannejad A, Behzadnia H, Emamhadi M. Simultaneous Diffuse Idiopathic Hyperostosis, Ossification of the Posterior Longitudinal Ligament and Ligamentum Flavum. Iran J Neurosurg. 2018; 4(1):51-55.

doi : http://dx.doi.org/10.32598/irjns.4.1.51

Funding: See Page 54

(c) Copyright: The Author(s)

Article info:

Received: 10 August 2017

Accepted: 25 November 2017

Available Online: 01 January 2018

Keywords:

Diffuse idiopathic skeletal hyperostosis, Ossification of the posterior longitudinal ligament, Ligamentum flavum, Diabetes mellitus

\section{ABSTRACT}

Background and Importance: A 60-year-old diabetic man with simultaneous diffuse idiopathic hyperostosis, massive ossification of the posterior longitudinal ligament and cervical and higher part of thoracic ligamentum flavum is reported in this article. Such comorbidity rarely occurs.

Case Presentation: The patient's chief complaint was sensation abnormalities without gait disturbance or severe cord compression symptoms despite the advanced stage of the disease. Computed tomography scan and magnetic resonance imaging confirmed multi-level involvement of cervicothoracic spine.

Conclusion: After surgical treatment, his symptoms resolved completely with no complication.

\section{Background and Importance}

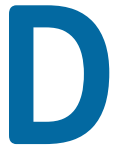

iffuse Idiopathic Skeletal Hyperostosis (DISH), also known as Forestier disease, is a disorder in which ossification of the anterolateral longitudinal ligament occurs, resulting in neurologic problems [1]. This abnormality appears to be higher in the middle-aged men than women [1]. DISH is rarely accompanied with Ossification of the Posterior Longitudinal Ligament (OPLL) and Ossification of the Ligamentum Flavum (OLF) [2]. OPLL characterized by calcification of the posterior longitudinal ligament [3] leads to cord compression [3]. OLF is a rare condition that can cause thoracic

\section{* Corresponding Author:}


myelopathy. Ligamentum flavum lies between two adjacent laminas over an epidural fat layer [4].

DISH, OPLL, and OLF often involve thoracolumbar, cervical, and lower thoracic spine, respectively [5]. All of three above mentioned diseases are frequent in men and the elderly $[3,4,6]$. However, genetic links between them is unclear [3]. In this article, we have reported a diabetic middle-aged man suffering from a combination of DISH, massive OPLL and, upper thoracic and cervical OLF.

\section{Case Presentation}

A 60-year-old diabetic Middle Eastern man with the chief complaint of chronic neck pain for 2 years presented with exacerbation of posterior neck pain and slight limitation in flexion and extension of cervical spine movements. He also experienced distal part paresthesia of his lower limbs during the past 2 weeks without feeling pain or motor malfunction.

Examination showed that power of all his upper and lower extremities were intact. Hypoesthesia of right arm and both lower extremities was noted. Other examinations including cranial nerves exam and deep tendon reflexes showed normal results. He reported no complaint of sphincter dysfunction.

Lateral neck X-ray showed two calcified longitudinal zone on the anterior and posterior sides of spine. Neck Computed Tomography (CT) scan and Magnetic Resonance Imaging (MRI) were performed, for further evaluation. Neck CT scan confirmed the calcification of anterior and posterior longitudinal ligaments with spinal canal stenosis at the level of C1-C2, C2-C3, C6-C7, and upper part of thoracic spinal canal. These findings were in favor of DISH and OPLL. Calcification of ligamentum flavum at the level of T1-T2 and T2-T3 was also noted (Figures 1 and 2).

Cervical MRI demonstrated large osteophytes in the anterior aspect of vertebrates with decreased cervical lordosis and calcification of posterior longitudinal ligament adjacent to odontoid process and body of $\mathrm{C} 2$ that resulted in compressive effect on thecal sac and narrowing of spinal canal. Bilateral narrowing of nerve root foramens at the level of C3-C4 and C6-C7, especially on the right side, was the reason for higher involvement of the right arm. MRI also confirmed affected ligamentum flavum adjacent to $\mathrm{C} 2$ and T2-T3 intervertebral space (Figures 3 and 4). Pelvic radiography showed DISH findings.

Surgical treatment consisted of posterior decompression of C1-C2 and laminectomy of C5-C6, T1-T2, T2-T3 as well as posterior fixation of $\mathrm{C} 2-\mathrm{C} 3, \mathrm{C} 4-\mathrm{C} 5, \mathrm{C} 6-\mathrm{C} 7, \mathrm{~T} 1-$ $\mathrm{T} 2$, and T2-T3 with screws and rods. Anterior longitudinal ligament was left untouched to decrease surgical complexity and complication at this session. Pathologic evaluations showed fibroconnective tissue admix with normal trabecular bone structures and bone marrow and confirmed clinical diagnosis of OLF and OPLL. Six months later, and on follow up, the patient was asymptomatic and sensation abnormalities were completely resolved with no other complication present.

\section{Discussion}

Compressive myelopathy can occur in OLF and OPLL [7] and contemporary occurrence of OPLL and OLF and DISH has also been reported [2]. DISH is a common spinal disorder involving about $12 \%$ of the middleaged men [8] but it occurs more frequently in diabetic patients and its symptoms present in $25 \%$ of diabetic patients [9]. The incidence of OPLL $(2.4 \%$ in the Asian
A

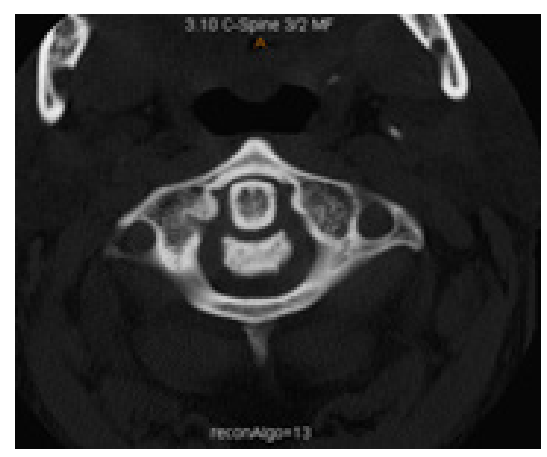

Figure 1. Cervical CT scan
$B$

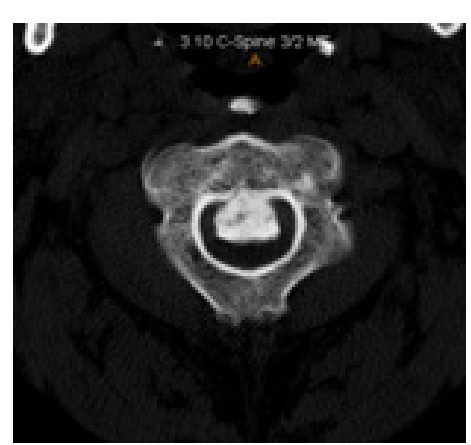

C



A and B show Large OPLL at the level of $\mathrm{C} 2$ and C3, respectively with spinal canal stenosis; C. Ossification of anterior longitudinal ligament at the level of C2 to C7 and OPLL at the level of C2-C3 and C6-C7 and T1-T2 and OLF of C2-C3 and T1-T2 


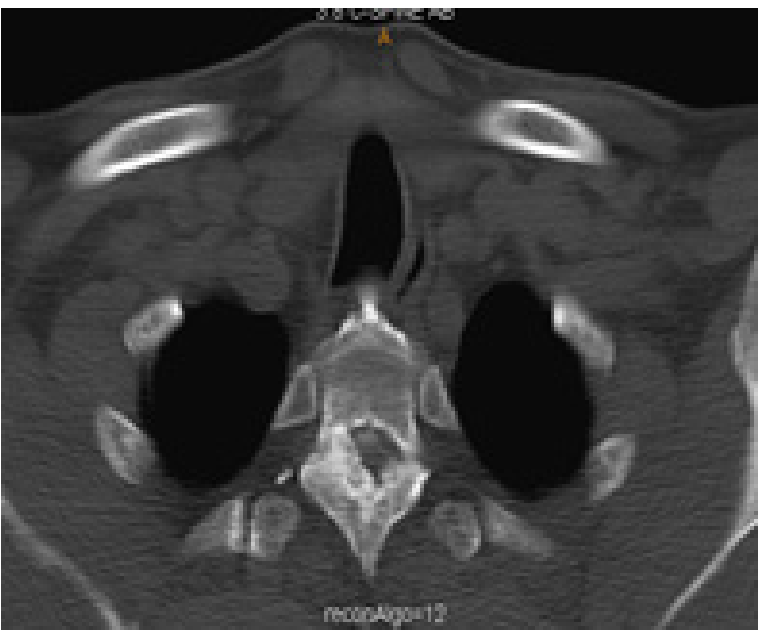

Figure 2. Thoracic CT scan shows OLF at the level of T2

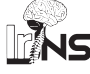

population) is more than OLF and less than DISH $[4,10$, $11]$, and combination of all is very rare [2].

Multifactorial etiology has been considered for DISH and OPLL $[1,3]$ but the distinctive causes are unclear. Some possible factors in OPLL as discussed in several studies including involvement of human collagen A2 gene on chromosome $6 p[12]$, stimulation of Bone Morphogenic Protein (BMP), especially BMP-2 [13] and TGF- $\beta 1$ polymorphism [14].

Over expression of insulin-like growth factor and growth hormone are considered as possible causes of new bone formation in DISH and OPLL $[15,16]$. So, the association between DISH and OPLL may be attributable to diabetes. Therefore, glycemic control should be recommended to diabetic patients [17]. Commonly DISH is

A

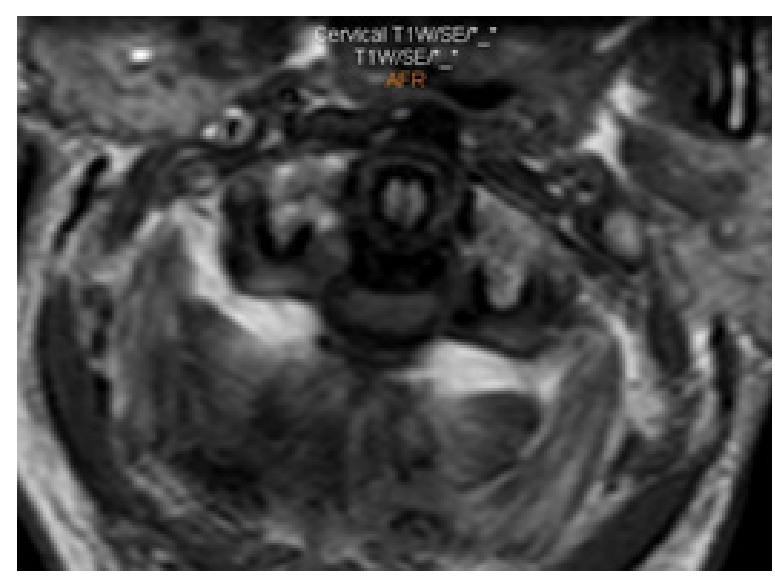

Figure 3. MRI of cervical spine asymptomatic and despite advanced involvement on radiologic imaging, patients complain modest symptoms [18]. Symptomatic patients generally suffer from back pain and limited motions, and rarely dysphagia and airway obstructive symptoms in advanced disease [19].

In addition to DISH, patients with OPLL may be asymptomatic despite suffering from up to $60 \%$ spinal canal stenosis [3]. As the disease progresses, symptoms including sensation abnormalities such as dysesthesia and clumsiness of upper extremities, will appear. Finally, neurologic deficit and abnormal gait reveal. Both DISH and OPLL prone the patient to compromise severely with minor trauma [20-22] and high mortality rate [23]. OLF also progresses gradually, and when the patient becomes symptomatic, compressive myelopathy, local pain and decreased mobility will develop [4].

Surgery is recommended for the treatment of OPLL, once myelopathy develops. Surgery can be done via anterior or posterior approach. Anterior approach is reasonable in the case of occupied OPLL is greater than $60 \%$ but due to technical problems, this approach is difficult to use when $\mathrm{C} 2$ or $\mathrm{T} 1$ are involved or the disease expands to some segments [3].

Posterior approach can be performed safely if severe extensive spinal cord compression persists [3] and applies by laminectomy, laminectomy and fusion or laminoplasty. Laminectomy and fusion can stabilize the spinal canal more than laminectomy alone. Laminoplasty reduces the risk of post-operation kyphotic deformity and neurologic problems [3]. In the case of OLF, as symptoms appear, surgical decompression is mandatory [4].

B

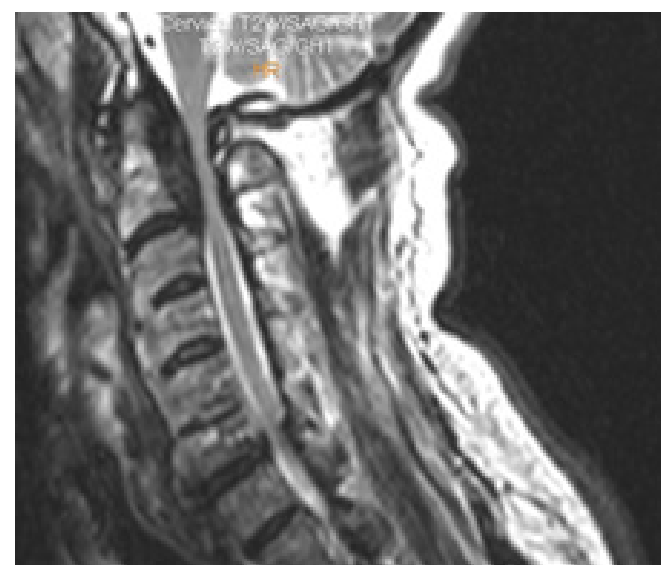

INS

A. Cord compression due to OPLL at the level of C2; B. Large osteophytes at the anterior aspect of C2 and C6 and calcified thickening of the posterior longitudinal ligament and OLF at the level of C2-C3 resulted in spinal canal stenosis 
A

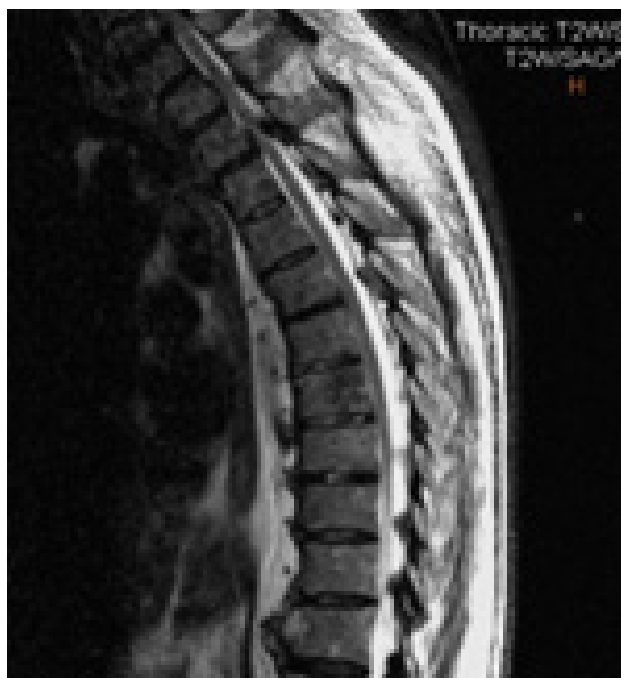

B

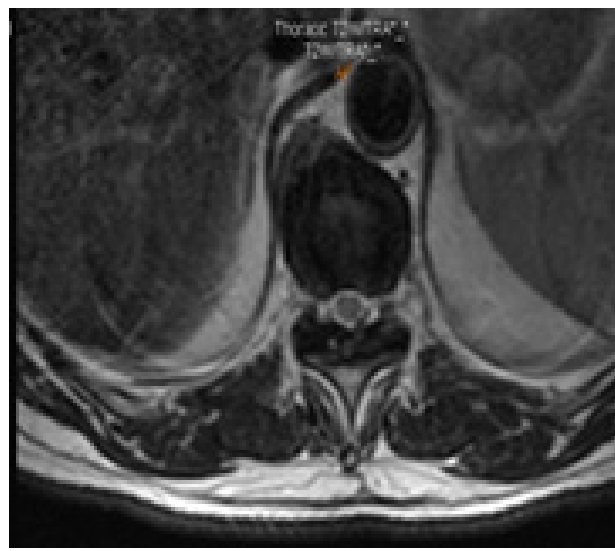

Figure 4. Thoracic MR

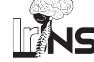

A. OPLL and OLF at the level of T2-T3; B. OLF at the level of T2

In our report, the patient was suffering from a rare combination of diabetes mellitus type 2 , massive retroodontoid OPLL and upper thoracic OLF. Although advanced involvement of thoracic and cervical spine was found on imaging, he had no gait disturbance or severe neurologic deficit. This could be explained by chronicity of the disease and timely surgical treatment.

\section{Conclusion}

Compressive myelopathy as a result of OLF and OPLL can occur in combination with DISH in rare cases. This study presented a rare case of diabetes mellitus, DISH, OPLL and OLF with no severe neurological deficit despite the advanced status of the disease. The patient sensation symptoms resolved after surgical procedure for OPLL and OLF.

\section{Ethical Considerations}

\section{Compliance with ethical guidelines}

Written informed consent form was obtained from the patient before the operation and for the rest of th procedure.

Funding

This research did not receive any specific grant from funding agencies in the public, commercial, or not-forprofit sectors.

\section{Conflict of interest}

The authors declared no conflict of interest.

Babak Alijani: Conception and design, Critically revising the article, Reviewing submitted version of manuscript/ Approving the final version of the manuscript; Shahrokh Yousefzadeh-Chabok: Conception and design, Critically revising the article, Reviewing submitted version of manuscript/Approving the final version of the manuscript; Armin Ramzannejad: Data Collection/Drafting the article/ Critically revising the article; Hamid Behzadnia: Conception and design, Critically revising the article, Reviewing submitted version of manuscript/Approving the final version of the manuscript; Mohammadreza Emamhadi: Conception and design, Critically revising the article, Reviewing submitted version of manuscript/Approving the final version of the manuscript.

\section{References}

[1] Storch MJ, Hubbe U,Golcker FX. Cervical myelopathy cause by softtissue mass in diffuse idiopathic skeletal hyperostosis. European Spine Journal. 2008; 17(2):243-47. [DOI:10.1007/s00586-007-05086] [PMID] [PMCID]

[2] Guo Q, Ni B, Yang J, Zhu Z, Yang J. Simultaneous ossification of the posterior longitudinal ligament and ossification of the ligamentum flavum causing upper thoracic myelopathy in DISH: Case report and literature review. European Spine Journal. 2011; 20(2):195-201. [DOI:10.1007/s00586-010-1538-z] [PMID] [PMCID]

[3] Choi BW, Song KJ, Chang H . Ossification of the posterior longitudinal ligament: A review of literature. Asian Spine Journal. 2011; 5(4):267-76. [DOI:10.4184/asj.2011.5.4.267] [PMID] [PMCID]

[4] Ahn DK, Lee S, Moon SH, Boo KH, Chang BK, Lee Jl . Ossification of the ligamentum flavum. European Spine Journal. 2014; 8(1):89-96. [DOI:10.4184/asj.2014.8.1.89] [PMID] [PMCID]

[5] Resnick D, Guerra J Jr, Robinson CA, Vint VC .Association of Diffuse Idiopathic Skeletal Hyperostosis (DISH) and calcification and ossification of the posterior longitudinal ligament. American 
Journal of Roentgenology. 1978; 131(6):1049-53. [DOI:10.2214/ ajr.131.6.1049] [PMID]

[6] Fox TP, Desai MK, Cavenagh T, Mew E. Diffuse idiopathic skeleta hyperostosis: A rare cause of dysphagia and dysphonia. BMJ Case Reports. 2013; 202(6): 938-42. [DOI: 10.1136/bcr-2013-008978] [PMID] [PMCID]

[7] Shiguematsa YF, Souza ECC, Zimmermann AF, Castro GRW, Pereira IA, Neves FS. Thoracic myelopathy due to calcification of the ligamentum fl avumwith hyperproteinorachia and responsive to steroid therapy: Case report. Revista Brasileira de Reumatologia. 2012 52(3):438-46. [DOI:10.1590/S0482-50042012000300013]

[8] Littlejohn GO, Smythe HA. Marked hyperinsulinemia after glucose challenge in patients with diffuse idiopathic skeletal hyperostosis. The Journal of Rheumatology. 1981; 8(6):965-68

[9] Rosenbloom AL. Connective tissue disorders in diabetes. In: R.A. Defronzoet, editor. International Textbook of Diabetes Mellitus. Hoboken, New Jersey: John Wiley \& Sons; 2004. [DOI:10.1002/0470862092.d0912]

[10] Tsuyama N. Ossification of the posterior longitudinal ligamento the spine. Clinical Orthopaedics and Related Research. 1984; (184):71-84. [PMID]

[11] Wang MY, Thambuswamy M. Ossification of the posteriorlongitudinal ligament in non-Asians: Demographic, clinical, and radiographic findings in 43 patients. Neurosurg Focus. 2011; 30(3):E4. [DOI:10.3171/2010.12.FOCUS10277] [PMID]

[12] Koga H, Sakou T, Taketomi E, Hayashi K, Numasava T, Harata S. Genetic mapping of ossification of the posterior longitudinal ligament of the spine.The American Journal of Human Genetics. 1998; 62(6):1460-7. [DOI:10.1086/301868] [PMID] [PMCID]

[13] Kon T, Yamazaki M, Tagawa M, Tagawa M, Goto S, Terakado A et al. Bone morphogenetic protein-2 stimulates differentiation of cultured spinal ligament cells from patients with ossification of the posterior longitudinal ligament. Calcified Tissue International. 1997; 60(3):291-6. [DOI:10.1007/s002239900231] [PMID]

[14] Kawaguchi Y, Furushima K, Sugimori K, Inoue I, Kimura T. Association between polymorphism of the transforming growth factorbeta1 gene with the radiologic characteristic and ossification of the posterior longitudinal ligament. Spine. 2003; 28(13):1424-6. [DOI:10.1097/01.BRS.0000068245.27017.9F]

[15] Pal B. Rheumatic disorders and bone problems in Diabetes Mellitus. In: Williams G, Pickup JC, (Eds), Handbook of diabetes. Hoboken, New Jersey: Wiley-Blackwell; 2004.

[16] Song J, Mizuno J, Hashizume Y, Nakagawa H. Immunohistochemistry of symptomatic hypertrophy of the posterior longitudinal ligament with special reference to ligamentous ossification. Spinal Cord. 2006; 44(9):576-81. [DOI:10.1038/sj.sc.3101881] [PMID]

[17] Ghosh B, Kishore S, Vijay V, Ramachandran A. Diffuse Interstitial Skeletal Hyperostosis (DISH) in type 2 diabetes. The Journal of the Association of Physicians of India. 2004; 52:994-6.

[18] Taurog JD. Ankylosing spondylitis, reactive arthritis, and undifferentiated spondyloarthropathy. In: Kasper D, Fauci A, Hauser S, Longo D, Jameson JL, Loscalzo J, (Eds), Harrison's principles of internalmedicine. Pennsylvania: McGraw-Hill; 1998.

[19] Verlaan JJ, Boswijk BJ, de Ru JA, Dhert WJR, Oner FC. Diffuse idiopathic skeletal hyperostosis of the cervical spine: An underestimated cause of dysphagia and airway obstruction. The Spine Journal. 2011; 11(11):1058-67. [DOI:10.1016/j.spinee.2011.09.014] [PMID]
[20] Hashizume Y, lijima S, Kishimoto H, Yanagi T. Pathology of spinal cord lesions caused by ossification of the posterior longitudinal ligament. Acta Neuropathologica. 1984; 63(2):123-30.

[21] Sreedharan S, Li YH. Diffuse idiopathic skeletal hyperostosis with cervical spinal cord injury: A report of 3 cases and a literature review. ANNALS Academy of Medicine Singapore. 2005; 34(3):257-61. [PMID]

[22] Westerveld LA, Verlaan JJ, Oner FC. Spinal fractures in patients with ankylosing spinal disorders: A systematic review of the literature on treatment, neurological status and complications. European Spine Journal. 2009; 18(2):145-56. [DOI:10.1007/s00586-008-07640] [PMID] [PMCID]

[23] Ghani I. Functional outcome in dish asssociated with Opll and Dens Hypertrophy resulting in rapidly progressive hemiplegia: A case report. Journal of Spine. 2014; 3(191):2. [DOI:10.4172/21657939.1000191] 